\title{
The Status of Adjuvant and Neoadjuvant Melanoma Therapy, New Developments and Upcoming Challenges
}

\author{
Henner Stege ${ }^{1} \cdot$ Maximilian Haist $^{1} \cdot$ Ulrike Nikfarjam $^{1} \cdot$ Michael Schultheis $^{1} \cdot$ Jaqueline Heinz $^{1} \cdot$ Saskia Pemler $^{1}$. \\ Carmen Loquai ${ }^{1} \cdot$ Stephan Grabbe ${ }^{1}$
}

Accepted: 30 August 2021 / Published online: 23 September 2021

(c) The Author(s) 2021

\begin{abstract}
The global incidence of malignant melanoma, the leading cause of skin cancer death, has steadily increased in recent years. Surgical excision is the treatment of choice for early-stage melanoma. However, $40-60 \%$ of patients with highrisk melanoma or with nodal involvement eventually experience loco-regional relapse or tumor progression. Adjuvant therapy aims to reduce the rate of recurrence in radically operated high-risk patients with melanoma and thus improves survival. Interferon- $\alpha$ has long been the only approved drug for adjuvant melanoma therapy, despite an unclear survival benefit. The landmark success of immune-checkpoint inhibitors and BRAF/MEK-directed targeted therapies in the treatment of patients with stage IV melanoma led to the initiation of clinical trials in the adjuvant setting. These trials demonstrated the efficacy of immune-checkpoint inhibitors and targeted therapies for the adjuvant treatment of highrisk patients with melanoma, as shown both by an increase in recurrence-free survival and the emergence of long-term survivors, finally resulting in the approval of the cytotoxic T-lymphocyte antigen 4 inhibitor ipilimumab, PD1 inhibitors (nivolumab, pembrolizumab), and BRAF/MEK inhibitors for adjuvant melanoma therapy. This review aims to delineate the advances in adjuvant melanoma therapy, issuing particularly recent results from clinical trials. Moreover, we also discuss pending issues and future challenges, which comprise the adequate selection of adjuvant regimens for patient subgroups and the identification of markers likely to predict the individual response to adjuvant treatments. Last, we outline the role of emerging neoadjuvant approaches, which may complement adjuvant strategies and are currently investigated in clinical trials.
\end{abstract}

\section{Introduction}

The incidence of malignant melanoma has increased dramatically in the past decades, and melanoma still has one of the fastest growing incidence rates among all malignant tumors in the Western world. At the same time, melanoma is responsible for over $90 \%$ of skin cancer deaths owing to its tendency to metastasize early [1]. In clinical practice, melanomas usually present in early clinical stages (stages I and II), which are defined by the absence of lymph node (LN) metastasis in the American Joint Committee on Cancer

Henner Stege, Maximilian Haist, Carmen Loquai and Stephan Grabbe contributed equally to this work.

Henner Stege

Henner.Stege@unimedizin-mainz.de

1 Department of Dermatology, University Medical Center of the Johannes Gutenberg University, Mainz, Germany

\section{Key Points}

Adjuvant therapy for high-risk patients with stage IIIA-IIID melanoma shows high efficacy and improves relapse-free survival.

Adjuvant therapy with nivolumab or pembrolizumab demonstrated a significant prolongation of relapsefree survival while providing a good safety profile for patients with high-risk melanoma.

Adjuvant therapy with BRAF/MEK inhibitors should be preferred for patients with BRAF-mutant non-ulcerated stage III melanoma.

classification [2, 3]. Surgical resection with an appropriate safety margin and subsequent sentinel LN biopsy provide a good prognosis particularly for stage I (melanoma-specific 
5-year survival rate: 97-99\%). Notably, however, patients with early-stage II melanoma may eventually experience a tumor relapse in the course of longer follow-up periods and show a melanoma-specific 5-year survival of $87-94 \%$ [3]. Hence, in order to allow for an objective evaluation of the risk for tumor relapse after initial surgical excision, longer follow-up periods may be required for these patients. Meanwhile, patients with thick ulcerated primary melanomas (IIC) and those patients showing regional LN metastases are classified as high-risk melanomas (stage III) and are associated with higher mortality [4]. Radical LN dissection and subsequent radiotherapy (RT) have long been considered the common scheme in the case of existing LN metastases [5, 6]. However, the concept of RT in the treatment of completely resected nodal or primary melanoma has been challenged by randomized controlled trials and little evidence supports the risk/benefit ratio for adjuvant $\mathrm{RT}$ in these patients today $[7,8]$. Hence, prior to the introduction of adjuvant systemic therapy, radical LN dissection remained the treatment of choice for patients with regional LN metastasis, while RT was considered a valuable treatment option only for patients showing unresectable melanoma or when surgery was not radical [9].

Following LN metastases, there is a dramatic increase in the risk for the occurrence of organ metastases, regardless of whether surgical resection of the primary tumor or the affected LN has taken place previously [10-12]. In this regard, it has been shown that patients with stage IIID have a melanoma-specific 5-year survival of approximately $32 \%$ and a 1-year rate of recurrence-free survival (RFS) of $42.1 \%$ [13] [3, 10, 14]. Because of the increasing risk of tumor progression in the case of $\mathrm{LN}$ metastases, the adjuvant application of systemic therapies, which aim to minimize the risk of tumor progression [15] is an attractive concept. These considerations similarly apply to patients with stage IIC melanoma, who are at a higher risk of disease progression compared with patients at stage IIIA (5-year survival $82 \%$ vs $93 \%$ ) [16, 17].

Adjuvant melanoma therapy was initially investigated using dacarbazine and bacillus Calmette-Guerin. This treatment, however, did not significantly improve overall (OS) or RFS of patients with melanoma [18]. Hence, the systemic application of interferons (IFN) represented the only effective therapeutic option used in the dermato-oncological routine until the advent of immune-checkpoint inhibitors (ICI) and BRAF/MEK-directed targeted therapy (TT) [19]. Interferons exert diverse effects both on immune cells, including myeloid and lymphoid cells, as well as on tumor cells, endothelial cells, and others. Depending on the particular cell type, IFN- $\alpha$ was found to induce distinct gene expression profiles, resulting in innate immune activation [20], dendritic cell stimulation, and subsequent induction of Th1-type T-helper cells [21], decreased secretion of vascular endothelial growth factor [22], and overexpression of major histocompatibility complex I [23]. First trials investigating adjuvant therapy with IFN- $\alpha 2 b, 2 a$, or pegylated IFN showed a significant sustained effect on RFS, but only marginal improvements in OS, while revealing a marked concomitant toxicity [24]. In particular, the EORTC 18991 phase III trial demonstrated a significant improvement in RFS (hazard ratio [HR]: 0.82, $p=0.01$ ) for patients with stage III melanoma receiving adjuvant pegylated IFN- $\alpha 2 b$ as compared with placebo, finally leading to US Food and Drug Administration approval [24]. In further trials, the best response to adjuvant IFN treatment was being observed in patients with ulcerated melanoma, suggesting that ulceration of the primary tumor may serve as an overriding predictive factor for IFN sensitivity $[25,26]$. Moreover, long-term follow-up results from the EORTC 18991 trial revealed a diminished impact of adjuvant pegylated IFN- $\alpha 2 b$ as compared with the benefit seen in the initial trial results and showed only a marginally significant impact on RFS, whereas no increase in OS or distant metastasis-free survival has been observed [27]. Therefore, the use of IFN- $\alpha$ has significantly declined in recent years and is currently only available in the pegylated form for off-label use [28, 29]. In the following, we provide a comprehensive review on the advances in adjuvant melanoma therapy that have been achieved since the advent of ICI and TT (Fig. 1; Table 1).

\section{Adjuvant Immunomodulatory Therapy}

The advent of ICI-based immunotherapy has significantly improved the treatment of metastatic malignancies [10]. Checkpoint molecules are fundamental components for maintaining immunologic self-tolerance [30], controlling the duration and magnitude of immune responses and thus preventing tissue damage from an excessive immune response [31]. Notably, malignant tumors may mimic this immune regulatory mechanism by expressing checkpoint molecules themselves and via the accumulation of immunoregulatory cells, which show a strong expression of checkpoint molecules. Checkpoint molecules may be discriminated by their ability to affect [1] the priming and activation of $\mathrm{T}$ cells in the LN or [2] whether they specifically inhibit an effective anti-tumor immune response in the tumor microenvironment [32-35].

The checkpoint molecule cytotoxic T-lymphocyte antigen 4 (CTLA-4) is a member of the B7/CD28 family that controls $\mathrm{T}$-cell functions. It is constitutively expressed by regulatory $\mathrm{T}$ cells but can also be upregulated by $\mathrm{CD} 4+\mathrm{T}$ cells upon activation. Cytotoxic T-lymphocyte antigen 4 competes with the co-stimulatory receptor $\mathrm{CD} 28$ for the ligation to CD80/86, which is expressed on antigen-presenting cells [36]. Because of the higher affinity of CTLA-4 to CD80/86, 


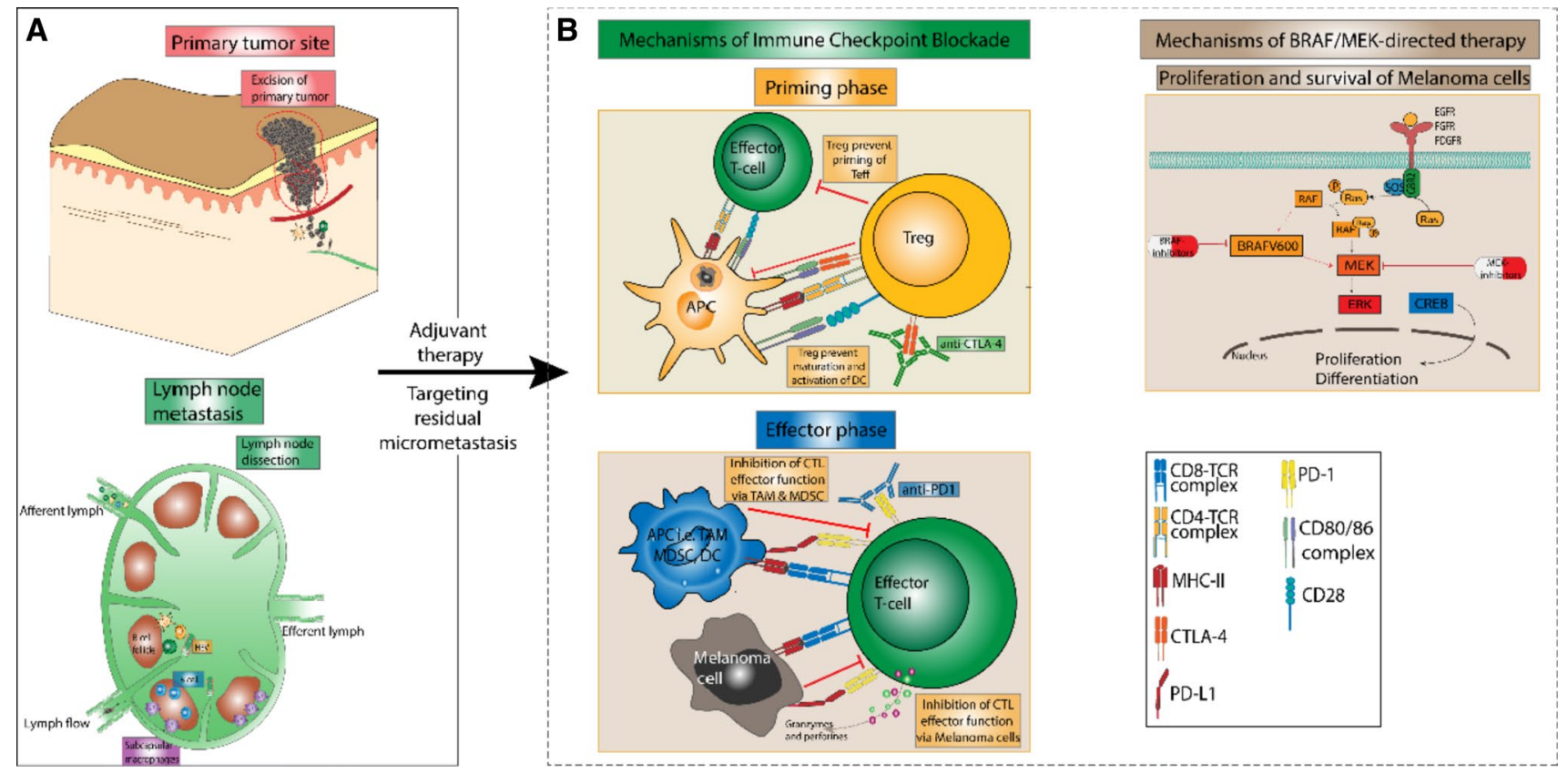

Fig. 1 Schematic overview of the concept of adjuvant melanoma therapy and its underlying mechanisms of action. Following the initial excision of the primary tumor and if necessary existing lymph node metastasis (A), the adjuvant application of either immunecheckpoint inhibitors or BRAF/MEK-directed targeted therapy can be considered for patients with stage IIC-IIID melanoma (B). Immunecheckpoint inhibitors reinforce the anti-tumor immune response to melanoma cells both in peripheral lymph nodes and the tumor microenvironment (left panel, B). Here, the anti- cytotoxic T-lymphocyte antigen 4 (CTLA-4) antibody ipilimumab mainly affects the priming and activation of $\mathrm{T}$ cells in lymph nodes (top center). By contrast, anti- programmed cell death protein 1 (PD-1) antibod-

it serves as a critical regulator limiting CD28-mediated signaling during antigen presentation, which results in an increased activation threshold for $\mathrm{T}$ cells and thus balances T-cell-mediated immune responses to antigens, such as tumor cell antigens [37-39]. The pivotal role of CTLA-4 as a molecule of immunologic self-tolerance [39] was impressively demonstrated in mice with CTLA-4 knockouts, which have shown severely exaggerated autoimmune responses resulting in lethal outcomes [40, 41]. Consistent with this finding, inhibition of CTLA-4 restored effective anti-tumor activity in both murine tumor models and humans [42-44].

\subsection{Ipilimumab}

In the first clinical trials investigating the effects of the CTLA-4 antibody ipilimumab (IPI), a substantial prolongation of OS has been observed in more than $20 \%$ in patients with metastatic melanoma with some patients even showing durable tumor responses [45]. In this regard, the EORTC study 18071 confirmed the efficacy of IPI in the adjuvant setting for patients with stage III melanoma. ies mainly serve to restore effector cell function of $\mathrm{T}$ cells within the tumor microenvironment via blockade of the T-cell bound checkpoint molecule PD-1 on effector T cells (bottom center). Targeted therapy confers anti-tumor activity via the blockade of the RAF-MEK-ERKsignaling cascade, thus disrupting melanoma cell proliferation and differentiation (right panel, B). Notably, both targeted therapy and immune-checkpoint inhibitor therapy target residual melanoma cells and micrometastases, which have not been cleared by initial excision, thus reducing the risk of melanoma progression in adjuvant therapy. $A P C$ antigen-presenting cells, $C T L, D C$ dendritic cell, $M D S C, M H C$ II major histocompatibility complex II, $P D-L 1$ programmed deathligand 1, TAM, Treg regulatory $\mathrm{T}$ cell

In particular, the initial application of IPI in four cycles of $10 \mathrm{mg} / \mathrm{kg}$ followed by 3 years of maintenance therapy with $10 \mathrm{mg} / \mathrm{kg}$ resulted in a significantly prolonged RFS and OS compared with placebo control (5-year RFS $40.8 \%$ vs 30.3\%; HR: 0.76 and 5-year OS 65.4 vs 54.4\%; HR: 0.58). However, a high incidence of severe treatment-related adverse events (CTCAE > grade 3/4; treatment-associated adverse events [trAE]) and a treatment-related mortality of $1 \%$ were observed [46]. Regarding the occurrence of trAE, the subsequent E1609 study demonstrated that IPI at a lower dose of $3 \mathrm{mg} / \mathrm{kg}$ was less toxic and resulted in a reduction of trAE (IPI $10 \mathrm{mg} / \mathrm{kg} 58 \%$ vs IPI $3 \mathrm{mg} /$ $\mathrm{kg} 36.4 \%$ ). Moreover, this trial demonstrated a significant improvement in OS and a non-significant trend towards a better RFS of IPI $3 \mathrm{mg} / \mathrm{kg}$ as compared with high-dose IFN treatment as an active control regimen. Notably, adjuvant treatment with IPI $10 \mathrm{mg} / \mathrm{kg}$ was more toxic and was not found superior in efficacy as compared to adjuvant IFN [14, 47]. Based on the efficacy data of IPI, the US Food and Drug Administration approved IPI $10 \mathrm{mg} / \mathrm{kg}$ as an adjuvant therapy for patients with stage III melanoma 
Table 1 Summary of the results from the randomized clinical trials reported for adjuvant melanoma therapy

\begin{tabular}{|c|c|c|c|c|c|c|c|c|}
\hline Authors & Trial & Regimen & Patients $(N)$ & $\begin{array}{l}\text { AJCC 7th Edi- } \\
\text { tion stages }\end{array}$ & $\begin{array}{l}\text { HR } \\
\text { RFS }\end{array}$ & HR OS & $\begin{array}{l}\text { 18-months } \\
\text { RFS }\end{array}$ & 3-year RFS \\
\hline \multicolumn{9}{|c|}{ Immunomodulatory therapy } \\
\hline $\begin{array}{l}\text { Eggermont } \\
\text { et al. [46] }\end{array}$ & EORTC 18071 & $\begin{array}{l}\text { Ipilimumab } \\
10 \mathrm{mg} / \mathrm{kg} \text { vs } \\
\text { placebo }\end{array}$ & 951 & $\mathrm{III}(>1 \mathrm{~mm})$ & 0.75 & 0.72 & - & $46.5 \%$ vs $34.8 \%$ \\
\hline $\begin{array}{l}\text { Weber et al. } \\
\text { [48] }\end{array}$ & CheckMate 238 & $\begin{array}{l}\text { Nivolumab } \\
3 \mathrm{mg} / \mathrm{kg} \text { vs } \\
\text { ipilimumab } \\
10 \mathrm{mg} / \mathrm{kg}\end{array}$ & 906 & IIIB-IIIC/IV & 0.65 & NA & $\begin{array}{c}66.4 \% \text { vs } \\
52.7 \%\end{array}$ & - \\
\hline $\begin{array}{l}\text { Eggermont } \\
\text { et al. [73] }\end{array}$ & KeyNote 054 & $\begin{array}{l}\text { Pembrolizumab } \\
200 \mathrm{mg} \text { vs } \\
\text { placebo }\end{array}$ & 1019 & III (> $1 \mathrm{~mm})$ & 0.57 & NA & $\begin{array}{c}71.4 \% \text { vs } \\
53.2 \%\end{array}$ & - \\
\hline $\begin{array}{l}\text { Tarhini et al. } \\
\text { [47] }\end{array}$ & ECOG 1609 & $\begin{array}{l}\text { Ipilimumab } \\
10 \mathrm{mg} / \mathrm{kg} \text { vs } \\
\text { Ipilimumab } \\
3 \mathrm{mg} / \mathrm{kg} \text { vs } \\
\text { High-dose } \\
\text { IFN- } \alpha 2 \mathrm{~b}\end{array}$ & 1670 & $\begin{array}{l}\text { IIIB, IIIC, IV, } \\
\text { M1a-b }\end{array}$ & $\begin{array}{l}1.0 \\
0.85(0.66- \\
1.09)\end{array}$ & $-\overline{0.78}$ & $\begin{array}{l}- \\
59 \% \\
52 \%\end{array}$ & $\begin{array}{l}- \\
53 \% \\
46 \%\end{array}$ \\
\hline $\begin{array}{l}\text { Targeted } \\
\text { therapy }\end{array}$ & & & & & & & & 2-year RFS \\
\hline Long et al. [76] & COMBI-AD & $\begin{array}{l}\text { Dabrafenib/ } \\
\text { trametinib vs } \\
\text { placebo }\end{array}$ & 870 & $\begin{array}{l}\text { III (LN metas- } \\
\quad \text { tasis > } 1 \mathrm{~mm})\end{array}$ & 0.47 & 0.57 & $67 \%$ vs $44 \%$ & $58 \%$ vs $39 \%$ \\
\hline Maio et al. [77] & BRIM8 & $\begin{array}{l}\text { Vemurafenib vs } \\
\text { placebo }\end{array}$ & 498 & $\begin{array}{l}\text { IIC, IIIA, IIIB } \\
\text { IIIC }\end{array}$ & 0.54 & NA & $\begin{array}{c}72.3 \% \text { vs } \\
56.5 \%\end{array}$ & - \\
\hline
\end{tabular}

AJCC American Joint Committee on Cancer, $H R$ hazard ratio, IFN interferon, $L N$ lymph node, $N A$ not available, $O S$ overall survival, $R F S$ recurrence-free survival

by 2015 . Because of its correlation with an increased incidence of trAE and the emergence of programmed cell death protein 1 (PD-1) antibodies as a more effective adjuvant therapy of patients with stage III melanoma, IPI $10 \mathrm{mg} / \mathrm{kg}$ has, however, not been granted approval in an adjuvant therapy setting in Europe [48, 49].

\subsection{Nivolumab}

Next to the blockade of CTLA-4 via IPI, anti-PD-1 antibodies pembrolizumab (Pembro) and nivolumab (Nivo) were found to significantly improve RFS and OS in the treatment of metastatic melanoma. In comparison to IPI, both PD-1 antibodies are characterized by higher response rates $>40 \%$ and a better side-effect profile. Notably, some patients even show durable tumor responses after cessation of anti-PD1 therapy, suggesting the ongoing restoration of an effective anti-tumor immune response upon application of PD-1 inhibitors $[29,50]$.

The checkpoint molecule PD- 1 is mainly expressed by T cells in the course of their activation and subsequently regulates their activity state [51-54]. Ligation of PD-1 to programmed death-ligand 1 (PD-L1) and programmed deathligand 2 (PD-L2), which are expressed by antigen-presenting cells, such as monocytes, macrophages, and dendritic cells, but also melanoma cells [55-58] results in the inhibition of T-cell effector function [36]. This occurs via intracellular activation of immunoreceptor tyrosine-based inhibitory motifs [59], decreased secretion of interleukin-2, IFN- $\gamma$, and tumor necrosis factor- $\alpha[60,61]$, decelerated cell-cycle progression [62-64], and a reduced expression of survivalpromoting proteins. In the course of chronic inflammation (i.e., chronic infections, tumor formation and progression), an upregulation of PD- 1 on T cells, B cells, and myeloid cells is frequently being observed, resulting in a profound regulation of the adaptive immune response $[65,66]$.

The efficacy of the anti-PD-1 antibody Nivo for adjuvant melanoma therapy was investigated in the CheckMate 238 study. This randomized double-blind trial demonstrated the superiority of adjuvant therapy with Nivo compared with IPI in stage IIIB/C and IV. A total of 906 patients were enrolled in the study and were treated either with Nivo $3 \mathrm{mg} / \mathrm{kg}$ or IPI $10 \mathrm{mg} / \mathrm{kg}$ for 12 months. Discontinuation of therapy occurred in the event of tumor progression or severe side effects. The primary endpoint of the CheckMate 238 study was RFS, secondary endpoints included OS and the incidence of trAE. Adjuvant therapy with Nivo resulted in a significantly improved RFS compared with IPI (RFS at 
12 months: $70 \%$ vs $60 \%$; 24 months: $63 \%$ vs $50 \%$; ), a better tolerability with fewer severe side effects ( $14.4 \%$ vs $45.9 \%)$, and less treatment discontinuations because of therapyrelated side effects $(9.72 \%$ vs $42.6 \%)$. Particularly referring to the enrollment of a less favorable population of patients in terms of clinicopathological factors (stage IIIB, C, and IV), the results of the Checkmate 238 trial may be considered even more remarkable [48, 67-69]. The recently published 4-year follow-up of the Checkmate 238 trial demonstrated sustained RFS with fewer irAE in patients with stage III/IV melanoma, who received adjuvant therapy with Nivo vs IPI (RFS $51.7 \%$ vs $41.2 \%$; HR: 0.71 [95\% confidence interval (CI) $0.60-0.86] ; p=0.0003 ;$ OS 77.9\% [95\% CI 73.7-81.5] vs $76.6 \%$ [72.2-80.3]; HR: 0.87 [95\% CI $0.66-1.14]$; $p=0.31$ ) [69]. However, no significant differences in OS have been observed between IPI and Nivo, which might be attributed to the variable impact of subsequent follow-up therapies upon tumor progression. Because the RFS currently serves as the primary endpoint for evaluating the efficacy of adjuvant therapies, the adjuvant application of Nivo can be considered more effective and compatible compared with IPI $[13,70]$.

\subsection{Pembrolizumab}

The efficacy of adjuvant Pembro therapy was evaluated in patients with clinical stage IIIA-IIIC melanoma and sentinel LN metastases $>1 \mathrm{~mm}$ (KEYNOTE-054 study). After randomization, 1019 patients received either Pembro $200 \mathrm{mg}$ or placebo every 3 weeks for 12 months or 18 cycles. Discontinuation criteria included tumor progression or the occurrence of non-tolerable side effects. Adjuvant therapy with Pembro resulted in a significant prolongation of RFS compared with placebo. The recent published 3.5-year follow-up of the KEYNOTE-054 clinical trial demonstrated a significantly improved RFS and distant-metastasis free survival (DMFS) in patients treated with Pembro in comparison with placebo (RFS 59.8\% [95\% CI 55.3-64.1] vs $41.4 \%$ [37.0-45.8]; DMFS, 65.3\% [95\% CI 60.9-69.5] vs 49.4\% [44.8-53.8]) [71]. Interestingly, the analysis of prespecified subgroups related to age ( $>65$ years), tumor stage (IIIA-C), PD-L1 expression (PD-L1 positive $65.3 \%$ vs PD-L1 negative $56.9 \%$ ), or BRAF mutation status (BRAF-V600E/K positive $62.0 \%$ vs BRAF wild-type $61.8 \%$ ) did not show significant differences in terms of RFS [72]. Therapy-related adverse events, such as fatigue (37.1\%), skin reactions $(28.3 \%)$, diarrhea $(19.1 \%)$, hypothyroidism $(14.3 \%)$, arthralgia (12.0\%), nausea $(11.4 \%)$, or hyperthyroidism $(10.2 \%)$, and treatment discontinuations were more frequently found in the Pembro $\operatorname{arm}(31.6 \%$ vs $18.5 \%$ and $13.0 \%$ vs $2.2 \%$ for trAE) [73].

Overall, clinical trials with adjuvant Pembro and Nivo demonstrated a significant prolongation of RFS for high-risk patients with melanoma. Therefore, the current guidelines of adjuvant melanoma therapy recommend the application of either a PD-1 inhibitor for a limited period of 12 months or until the occurrence of intolerable side effects or tumor progression [74]. Notably, both PD-1 inhibitors can be administered using higher dosages and with longer time intervals between each cycle without increasing the risk of side effects or loss of efficacy [75]. However, it should be noted that further prospective randomized controlled trials, comparing the high-dose regimen vs the currently established low-dose regimen, will be needed in order to establish the adjuvant safety and efficacy of the proposed treatment regimen.

\subsection{Combined Checkpoint-Inhibitor Therapy}

Considering the results of adjuvant ICI monotherapy in patients with resected stage III melanoma and the wellknown clinical response rates of a combined checkpoint inhibitor therapy (cICI) with IPI and Nivo in non-resectable stage III or IV melanoma, the indication for adjuvant cICI is currently being intensely discussed. A recently published phase II study demonstrated the superiority of cICI with Nivo $1 \mathrm{mg} / \mathrm{kg}$ plus IPI $3 \mathrm{mg} / \mathrm{kg}$ in stage IV patients compared with monotherapy with Nivo after complete resection of melanoma and without evidence of currently existing metastasis (no evidence of disease). Here, a total of 167 patients were randomized into three treatment arms: (1) IPI $3 \mathrm{mg} / \mathrm{kg}$ plus Nivo $1 \mathrm{mg} / \mathrm{kg}$, (2) Nivo $3 \mathrm{mg} / \mathrm{kg}$, and (3) placebo. After a median follow-up of 28.4 months, the median RFS was not reached in the IPI plus Nivo group, whereas median RFS was 12.4 months (95\% CI 5.3-33.3) in the Nivo group and 6.4 months (95\% CI 3.3-9.6) in the placebo group. In the same vein, the HR for recurrence in the IPI plus Nivo group vs placebo was 0.23 (97.5\% CI 0.12-0.45; $p<0.0001$ ), and for the Nivo group vs placebo was 0.56 $(0.33-0.94 ; p=0.011)$. However, significantly more patients with cICI therapy experienced grade $3 / 4$ trAE $(70.9 \%$ vs $26.8 \%$ for monotherapy and $5.9 \%$ in the placebo group). Discontinuation of therapy because of intolerable side effects occurred in $62 \%$ of patients receiving cICI therapy and in $13 \%$ of patients receiving Nivo monotherapy [83]. However, these positive results favoring IPI plus Nivo vs Nivo monotherapy in an adjuvant therapy setting in patients with stage III or IV melanoma could not be reproduced in the Checkmate 915 trial (NCT03068455), a larger scale, commercially sponsored, international phase III trial that compared the adjuvant therapy of IPI plus Nivo with Nivo monotherapy. In total, 1844 patients with completely resected stage IIIB-IV melanoma were randomized in a 1:1 ratio into a cohort receiving IPI $1 \mathrm{mg} / \mathrm{kg}$ every 6 weeks plus Nivo $240 \mathrm{mg}$ every 2 weeks or a cohort receiving Nivo monotherapy $480 \mathrm{mg}$ every 4 weeks. First results published in 2020 showed that the dual primary endpoints of this clinical trial were not met. While the RFS rate at the 3-year follow-up for 
cohort A was 70\% (95\% CI 45-85) vs 75\% (95\% CI 50-89) for cohort B. The median RFS was not reached in either group and did not reveal a significant difference between the two cohorts (HR: $0.92,95 \%$ CI $0.77-1.09, p=0.269$ ). Moreover, the current data showed similar outcomes after breaking down the patients into the melanoma stages III and IV. The RFS in patients with stage III melanoma after the 2-year follow-up was $64.7 \%$ in the cohort treated with IPI plus Nivo and $63.6 \%$ in the cohort treated with Nivo monotherapy. In the subgroup with stage IV melanoma, the 3-year and 2-year RFS rates were 74\% (95\% CI 48-88) and 80\% (95\% CI 55-92), respectively. Additionally, the treatment duration between the treatment cohorts was notably different, as patients who received the combination regimen had a median duration of therapy of 7.6 months vs 11.1 months in the Nivo-alone arm. Overall, these preliminary results show that IPI plus Nivo did not significantly improve the RFS or DMFS in patients with stage IIIB-IV melanoma and currently reaffirm Nivo monotherapy as the treatment regimen in an adjuvant setting [83].

\section{Adjuvant BRAF/MEK-Directed Targeted Therapy}

Next to ICI therapy, the clinical application of combined BRAF/MEK inhibitors has led to a widespread improvement in the therapeutic landscape for patients with metastatic melanoma in recent years. Of all patients with melanoma, 40-60\% harbor a BRAF mutation, most commonly affecting codon 600 (BRAF V600E) [84]. This mutation results in the constitutive activation of the RAF-MEK-ERK signal transduction pathway, which is critical for melanoma development and progression [85].

Following the approval of BRAF/MEK inhibitor treatment with dabrafenib (Dab) and trametinib (Tram) for metastatic melanoma, their application has also been extended to the adjuvant setting for patients with melanoma stage III by 2018 . The approval is based on a double-blind, placebocontrolled, phase III study that enrolled 870 patients with completely resected, high-risk stage III melanoma and BRAF V600E or V600K mutations. Adjuvant therapy was given for 12 months with Dab (300mg) plus Tram [2 mg] or placebo. Recurrence-free survival was defined as the primary endpoint, whereas OS, DMFS, RFS, and safety were defined as secondary endpoints. Combined BRAF/MEK inhibitor therapy showed a significantly improved RFS and DMFS as compared with the placebo group after a minimal follow-up of 59 months (58\% vs 39\%; HR: 0.47). However, the safety profile remained acceptable, largely showing similar results to those previously reported for patients with metastatic melanoma treated with Dab plus Tram [76]. The 5-year follow-up confirmed the longer survival without tumor reoccurrence or distant metastasis in patients treated with Dab plus Tram than placebo-treated patients (RFS 52\% vs 36\% [HR for relapse or death: 0.51 ; 95\% CI 0.42-0.61]; DMFS $65 \%$ vs $54 \%$ [HR for distant metastasis or death: 0.55 ; 95\% CI 0.44-0.70]). Notably, no apparent long-term irAE have been observed [86]. A second study tested the efficacy and tolerability of vemurafenib $960 \mathrm{mg}$ in the adjuvant setting for patients with stage IIC and III BRAFV600positive melanoma [77]. Here, 498 patients were enclosed and randomized into two cohorts. The primary endpoint was defined as RFS, and secondary endpoints included OS, DMFS, tolerability, and quality of life. Although both cohorts showed advantages for vemurafenib (median RFS 23 months vs 15 months), these results were not considered significant because the pre-specified endpoint was not met in one cohort.

\section{Outlook and Future Concepts}

Approximately $90 \%$ of all melanomas are diagnosed without evidence of existing distant metastasis. Following the occurrence of LN metastasis, melanoma-specific 10-year survival decreases from nearly $88 \%$ (IIIA) to $24 \%$ (IIID) [87]. Unfavorable prognostic factors for metastasis are tumor thickness and ulceration; accordingly, the recurrence rate of resected primary melanomas increases from approximately $5 \%$ for non-ulcerated small tumors $(<1 \mathrm{~mm})$ to over $40 \%$ for melanomas with tumor thickness $>4 \mathrm{~mm}$ and existing ulceration. In this regard, it has been shown that the melanoma-specific 10 -year survival and the risk for tumor recurrence is worse for patients with stage IIC (without LN metastasis) compared with stage IIIA (evidence of LN metastases) [88, 89].

\subsection{Adjuvant Therapy for Patients with Stage II Melanoma}

The beneficial results from adjuvant melanoma therapy in stage III patients provide hope that stage IIC patients may also benefit from adjuvant therapy [90, 91]. Hence, several phase III trials are currently investigating whether adjuvant ICI therapy using PD-1 antibodies improves RFS in stage II patients: these include the KEYNOTE-716 study (NCT03553836), which investigates the efficacy of a 12-month adjuvant therapy with Pembro $200 \mathrm{mg}$ for stage IIB/C patients. Here, RFS is defined as a primary endpoint, and secondary endpoints include OS and distant metastasisfree survival [84].

The efficacy of Nivo in an adjuvant setting for melanoma stage IIB/C is currently being analyzed in the CheckMate 76k phase III trial (NCT04099251). Similar to the KEYNOTE-716 trial, 12 months of therapy with Nivo 480mg or placebo will follow a 2:1 randomization. In the case of 
progression for patients included in the placebo arm, a crossover to Nivo therapy is possible.

The NivoMela study (NCT04309409) additionally allows for the enrollment of stage IIA patients alongside stage IIB-C patients. Using biomarker-based risk stratification, patients with high scores and thus an increased risk of recurrence receive Nivo or placebo. A low stratification leads to inclusion in the observation arm. Randomization is based on tumor stage (IIA vs IIB vs IIC), sex (female vs male), and location of the primary tumor (extremities vs trunk vs head and neck).

\subsection{Concepts of Neoadjuvant Melanoma Therapy}

Next to the promising results from adjuvant melanoma trials, the application of ICI in the neoadjuvant setting is currently under investigation, which might pose a new therapeutic alternative for patients with advanced melanoma (see Table 2). The efficacy of neoadjuvant therapy has already been demonstrated for various tumor entities [92-95]. The benefit of neoadjuvant treatment includes the reduction in tumor burden, thus resulting in an improved operability and control of locoregional metastasis. Additionally, it has been suggested that a neoadjuvant approach might enable the assessment of the individual responsiveness towards ICI therapy, thus gaining further information on potential mechanisms of tumor resistance [96, 97].

A first trial investigating the efficacy of neoadjuvant treatment reported a good anti-tumor immune response with a complete or partial response after a single dose of Pembro $200 \mathrm{mg}$ in a total of 8 of 27 patients with resectable stage IIIB/C or IV melanoma (no residual tumor, $n=5 ;<10 \%$ viable tumor cells, $n=3$ ). The treatment regimen involved a single dose of Pembro 3 weeks prior to curative surgery, followed by 12 months of adjuvant Pembro therapy. After a median follow-up of 25 months, all eight patients remained recurrence free. Recurrence-free survival and OS for the entire study cohort were estimated at $63 \%$ and $93 \%$, respectively [78].

Consistent with these results, another trial investigating the efficacy of cICI therapy in the neoadjuvant setting demonstrated strong overall response rates (ORR 73\%, pathological complete response [pCR] 45\%) as compared with Nivo monotherapy (ORR 25\%, pCR 25\%). Here, patients received either four doses of Nivo or three doses of combined ICI prior to surgical resection of the metastases. Surgery was followed by 6 months of adjuvant Nivo therapy ( $3 \mathrm{mg} / \mathrm{kg}$ every 2 weeks) in both groups. Despite the better ORR, grade 3 trAE have been more common for patients receiving cICI therapy as compared with monotherapy (73\% vs 38\%) [79].

More recently, the OpACIN trial (NCT02437279) evaluated the response to cICI therapy (Nivo $1 \mathrm{mg} / \mathrm{kg}$ plus IPI $3 \mathrm{mg} / \mathrm{kg}$ ) in the neoadjuvant setting (two doses prior to surgery and two doses thereafter) or the adjuvant setting (four doses) for patients with palpable LN metastases and clinical stage III. Neoadjuvant therapy with cICI resulted in good response rates in the affected LN metastases (ORR $80 \%$, pCR $60 \%<10 \%$ viable tumor cells) and an estimated 3 -year RFS of $80 \%$ for the neoadjuvant group and $60 \%$ for the adjuvant group. However, the application of cICI therapy has been accompanied by increased toxicity (trAE grade 3/4 $90 \%$ ), leading to discontinuation of therapy after the second or third cycle. Taking into consideration the high-grade toxicity found in the OpACIN trial, the OpACIN-neo trial (NCT02977052) provided neoadjuvant therapy with reduced doses of IPI and Nivo in patients with stage III melanoma with palpable LN metastases. In this trial, patients were randomized into three neoadjuvant study arms (Arm A: two doses of Nivo $1 \mathrm{mg} / \mathrm{kg}$ plus IPI $3 \mathrm{mg} / \mathrm{kg}$; Arm B: two doses of Nivo $3 \mathrm{mg} / \mathrm{kg}$ plus IPI $1 \mathrm{mg} / \mathrm{kg}$; Arm C: two doses of IPI $3 \mathrm{mg} / \mathrm{kg}$ followed by Nivo $3 \mathrm{mg} / \mathrm{kg}$ ), which was followed by radical LN dissection at 6 weeks. Primary endpoints were toxicity, pathological response, and clinical response. Within the first 12 weeks, the highest rate of trAE was found in patients receiving sequential therapy (Arm C: $50 \%$ vs Arm B: $20 \%$ vs Arm A: $40 \%)$. Hence, this study arm was closed early. The strongest response was reported for conventional cICI therapy (Arm A: 63\% showing a clinical response and $80 \%$ pathological response vs Arm B: $57 \%$ and $77 \%$ vs Arm C: $35 \%$ and $65 \%$ ). Although the median RFS of the OpACINneo trial has not been reached yet, 18-month RFS of all patients was estimated with $85 \%$ (Arm A: $90 \%$, Arm B: $82 \%$, Arm C: 83\%). Underscoring the general efficacy of neoadjuvant melanoma treatment using ICI is the observation that tumor progression was only found in $1.4 \%$ of patients showing an initial pathological response after a follow-up of 36 months in the OpACIN or OpACINneo trial.

Overall, the OpACIN trial demonstrated for the first time the potential benefit of neoadjuvant vs adjuvant ICI, while the OpACINneo trial demonstrated the good response of cICI. In particular, using lower doses of IPI ( $1 \mathrm{mg} / \mathrm{kg})$ plus Nivo (3 mg/kg), a significantly better tolerability with $20 \%$ of patients showing grade $3 / 4$ trAE has been observed, while response rates (pathological response rate $77 \%$ ) remained similar compared to conventional cICI with Nivo $1 \mathrm{mg} / \mathrm{kg}$ plus IPI $3 \mathrm{mg} / \mathrm{kg}[81,98,99]$.

Next to the efficacy of a neoadjuvant therapy within the conventional therapeutic concept, as analyzed by the OpACIN trial, it remains to be determined whether patients with an initial response to neoadjuvant cICI therapy (Nivo $3 \mathrm{mg}$ / $\mathrm{kg}$ plus IPI $1 \mathrm{mg} / \mathrm{kg}$ ) benefit from subsequent $\mathrm{LN}$ dissection. This issue will be addressed by the PRADO (Personalized Response-driven Adjuvant Combination of IPI and Nivo in Stage IIIIB/C melanoma) [NCT02977052] trial. The protocol included two cycles of neoadjuvant cICI with Nivo $3 \mathrm{mg} /$ $\mathrm{kg}$ plus IPI $1 \mathrm{mg} / \mathrm{kg}$, which is followed by LN dissection 


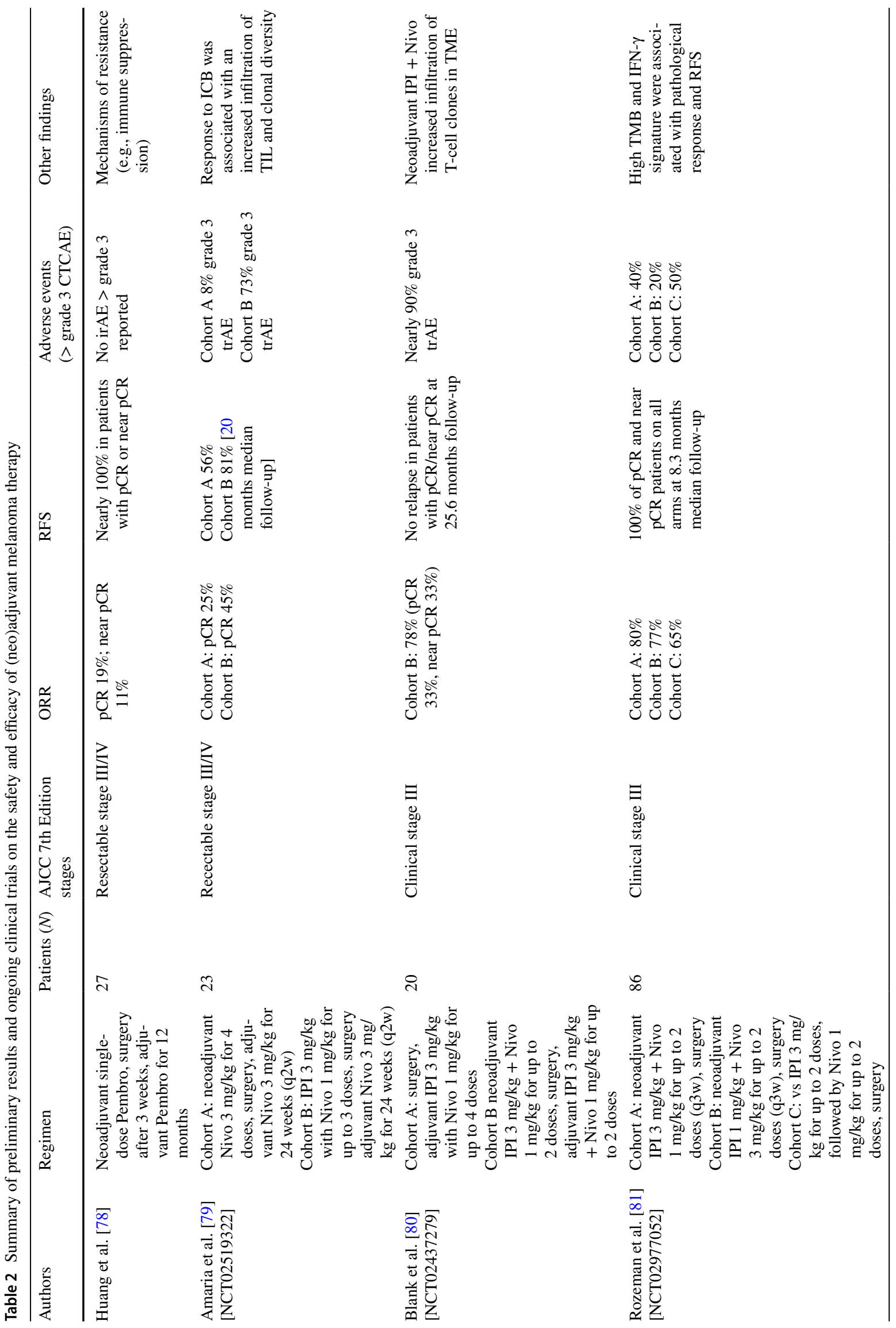




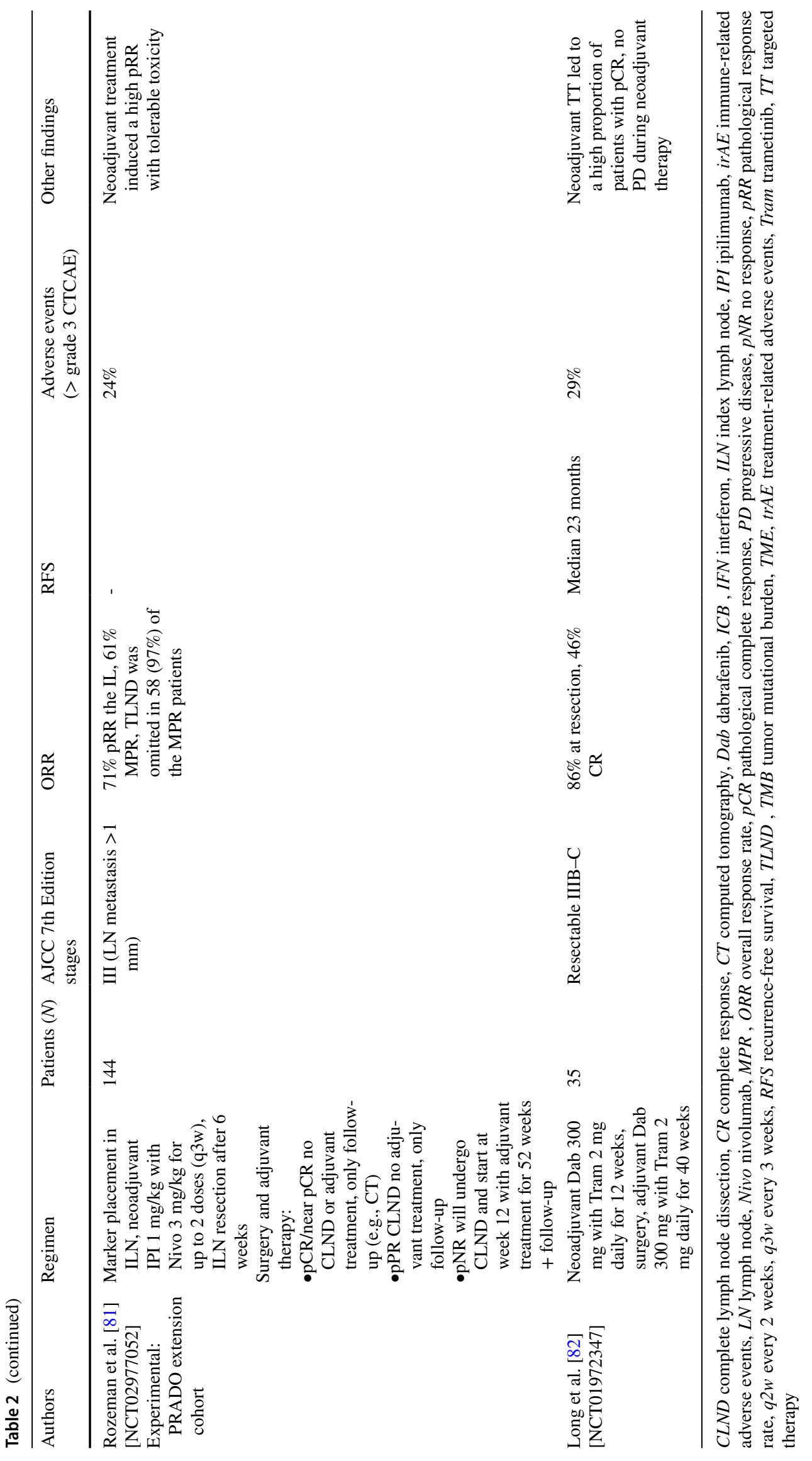


after 6 weeks. In the case of no pathological response to neoadjuvant treatment ( $>50 \%$ tumor cells), patients received LN dissection and 12 months of adjuvant therapy, which comprised either ICI or BRAF/MEK inhibitor therapy. By contrast, patients with pCR or almost complete response (detection of $<10 \%$ tumor cells) did not undergo LN dissection. Overall, pathological response was seen in $71 \%$, and pCR $(<10 \%$ tumor cells in the index LN) was observed in $60 \%[100,101]$. Further data regarding the efficacy of either treatment are currently pending.

Last, the NeoCombi trial (NCT01972347) investigated the efficacy of neoadjuvant BRAF/MEK inhibitor therapy for stage IIIB/C patients. To this end, patients received 12 weeks of neoadjuvant therapy with Dab (300 mg) plus Tram ( $2 \mathrm{mg}$ ) followed by radical LN dissection and 40 weeks of adjuvant therapy. Preliminary data revealed that $86 \%$ of patients showed a pathological response (pCR: $43 \%$, pPR: $40 \%$ ) at the time of LN dissection. These data suggest, that neoadjuvant BRAF/MEK inhibitor therapy might also be considered a feasible therapeutic option; however, therapeutic outcome of adjuvant TT was not as favorable as after neoadjuvant immunotherapy, as after a median follow-up of 12.1 months, tumor progression was being observed in $36 \%$ of patients [82]. Consistent with these data, interim data from the Combi-Neo (NCT02231775) trial revealed a significantly longer RFS (median RFS 19.7 months vs 2.9 months) for neoadjuvant Dab (300 mg) plus Tram (2 mg) treatment as compared with initial $\mathrm{LN}$ dissection followed by adjuvant therapy. Here, it has been investigated whether 8 weeks of neoadjuvant Dab/Tram therapy prior to LN dissection plus adjuvant BRAF/MEK inhibitor therapy might be beneficial as compared to LN dissection and subsequent adjuvant therapy only. After a median follow-up of 18.6 months, 10/14 patients receiving neoadjuvant BRAF/MEK inhibitor therapy showed an ongoing tumor response as compared with 0/7 patients for conventional treatment [102].

\section{Conclusions and Implications for Clinical Practice}

Recently, the advent of ICI therapy and TT has radically changed the concept of adjuvant melanoma therapy [14]: adjuvant therapy protocols involving ICI and BRAF/MEK inhibitors have proven to result in a significant reduction in the risk for tumor relapse in patients with stage III melanoma. Accordingly, adjuvant ICI or BRAF/MEK inhibitor therapy is an evidence-based therapeutic alternative and must be discussed with patients. Because a direct comparison of the two adjuvant regimens in patients with the BRAF mutation has not been performed to date, the treatment decision involves considerations on the various side-effect profiles, the preferred mode of application, and the individual efficacy in a physician-patient discussion [91]. Because of the different criteria for patient enrollment in trials involving ICI or BRAF/MEK inhibitor therapy, cross-over comparisons of primary endpoints should be avoided [48, 73, 76]. Hence, pre-existing conditions and treatment feasibility are the most common criteria included in the decision whether to choose adjuvant ICI or targeted therapy for patients with BRAF mutation [70]. For BRAF wild-type patients, by contrast, ICI remains the most promising adjuvant therapeutic option. Treatment with either Nivo or Pembro did not show significant differences in terms of RFS or ORR [72].

Although there is culminating evidence on factors that may predict a response to BRAF/MEK inhibitor therapy for patients with stage IV melanoma, such as normal levels of lactate dehydrogenase, low tumor burden, or lack of cerebral metastasis [103], there are currently no predictive markers that might serve as guideposts for adjuvant therapy in stage III patients. Further complicating the decision is the observation inferred from longer followup trials, which suggest that adjuvant TT might be inferior to ICI therapy in terms of long-term outcomes [91]. This finding does however somewhat contrast with recent reports showing a statistically significant prolongation of OS after adjuvant BRAF/MEK inhibitors but not after anti-PD-1, at least when compared to IPI. Therefore, existing comorbidities and tolerability play a significant role in decision making. While pre-existing cardiac conditions are of primary concern in BRAF/MEK inhibitor therapy [104, 105], the presence of autoimmune diseases should be clarified before initiating ICI therapy [106, 107]. The high incidence of mild therapy-associated side effects during targeted therapy, some of which may persist throughout the duration of therapy [76], should be considered before initiating adjuvant BRAF/MEK inhibitor treatment. By contrast, side effects during ICI therapy are less frequent, but more often result in treatment cessation and can sometimes cause serious complications, including death [67]. Thus, discontinuation of therapy because of $\operatorname{tr} \mathrm{AE}$ is more common with ICI therapy [73].

As $40-60 \%$ of patients with melanoma harbor a BRAF mutation, therapeutic decisions may additionally take into account the need for therapeutic sequencing [108]. Sequencing of BRAF/MEK inhibitor and ICI therapy might be particularly relevant regarding potential immunomodulatory effects found in patients with the BRAF mutation and conferred by BRAF/MEK inhibitors. In this context, it has been observed that patients with the BRAF mutation frequently show an immunosuppressive TME, which is characterized by a decreased activity of antigen-presenting cells and an overexpression of inhibitory cytokines such as interleukin-6 and interleukin-10 [109-111]. BRAF/MEK inhibitor therapy, by contrast, may promote a shift toward an immunogenic TME (Fig. 2) 


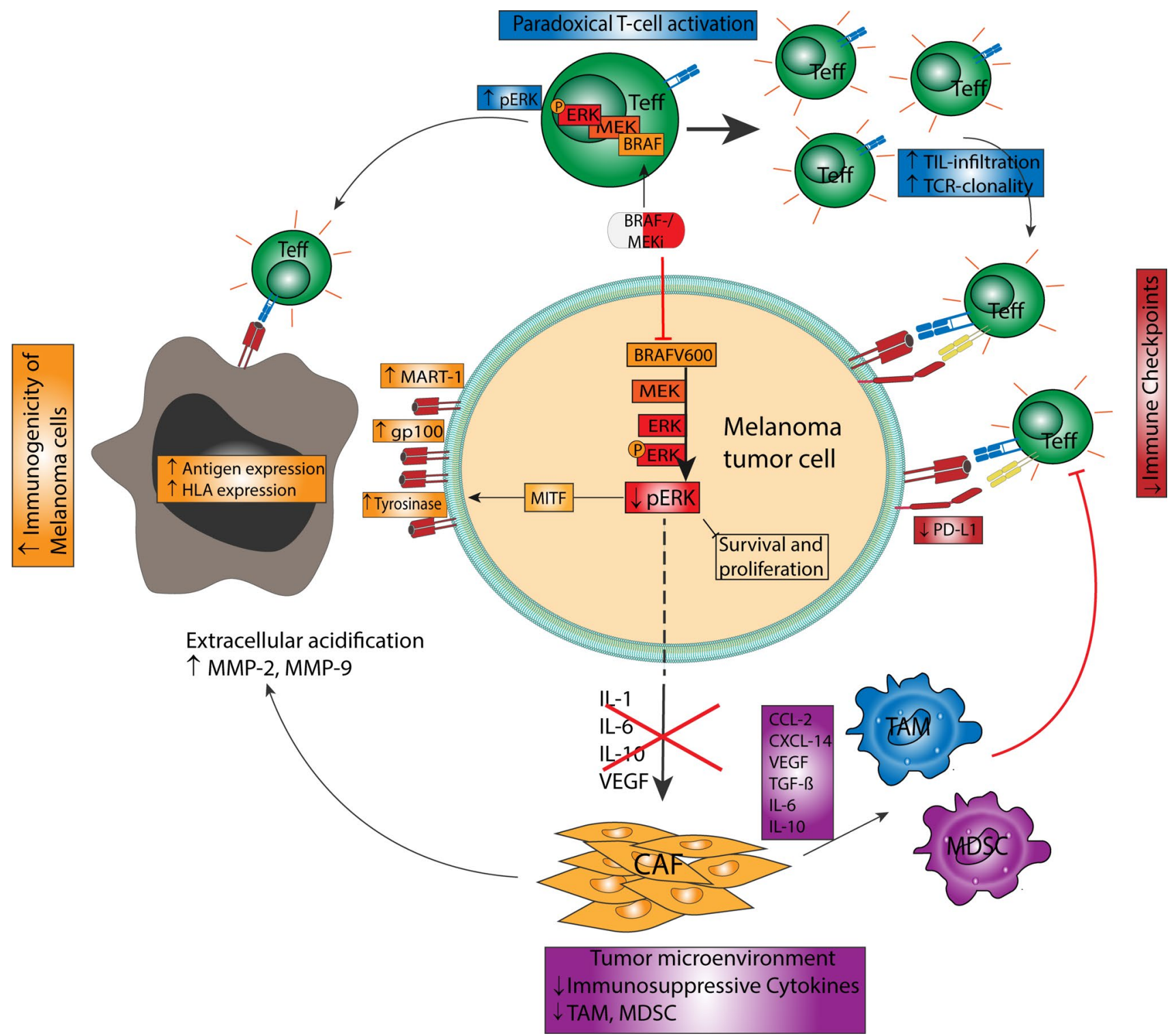

Fig. 2 Immunomodulatory effects of BRAF/MEK inhibitors in the context of melanoma therapy. Next to the direct antiproliferative effects conferred by targeted therapy, it has been found that these might further exert immunomodulatory properties within the tumor microenvironment. In particular, BRAF inhibition resulted in a stronger expression of tumor antigens, thus favoring the immunological recognition of melanoma cells. Furthermore, BRAF inhibitors were initially shown to reduce programmed death-ligand 1 (PD-L1) expression on melanoma cells. More importantly, BRAF inhibition may result in a paradoxical activation of effector $\mathrm{T}$ cells thus enhanc-

by favoring the infiltration of $\mathrm{CD} 8^{+} \mathrm{T}$ cells, the expression of tumor antigens, or PD-L1 expression on melanoma cells, while reducing the infiltration by regulatory $\mathrm{T}$ cells and MDSC [111-113]. Accordingly, it is debated whether sequential BRAF/MEK therapy followed by ICI therapy ing anti-melanoma immune response. Last, BRAF-MEK inhibitors were found to reduce the secretion of cytokines such as interleukin (IL)-1, IL-6, or IL-10, which impairs the infiltration of immunosuppressive tumor-associated macrophages and myeloid derived suppressor cells. Overall, BRAF/MEK inhibitors may therefore tip the scale towards an inflamed tumor microenvironment favoring an antimelanoma immune response. CAF, HLA human leukocyte antigen, MDSC, MMP, TAM, TCR, Teff, TIL, TGF- $\beta$ transforming growth factor- $\beta, V E G F$ vascular endothelial growth factor

may result in a better response to systemic treatment $[114$, 115].

However, the concept of neoadjuvant melanoma therapy represents another promising option for patients with advanced melanoma, as it has been found to efficiently 
reduce the tumor burden and thus improve operability. In this regard, preliminary clinical data revealed that patients with a pCR after neoadjuvant therapy were very likely to show persistent tumor responses [116]. Furthermore, neoadjuvant therapy allows for the early identification of mechanisms of tumor resistance, thus improving the subsequent therapeutic strategy [117]. However, it remains to be determined whether the initial data of the OpACIN study will be confirmed by subsequent trials and whether neoadjuvant treatment may additionally improve RFS as compared to adjuvant therapy. Another issue concerns the duration of neoadjuvant ICI therapy, which may be addressed in future trials [118]. Despite these yet unresolved issues, the introduction of ICI and BRAF/MEK inhibitor therapy has opened new possibilities for both adjuvant and neoadjuvant melanoma therapy. Further studies now need to clarify which patients might particularly benefit from neoadjuvant or adjuvant therapy and which treatment protocols might show the best efficacy for individual patient subgroups.

\section{Declarations}

Funding Open Access funding enabled and organized by Projekt DEAL. S.G. is funded by the German Research Council (SFB 1066, B4, B5) and by the German Research Council (SFB TR156, B11). H.S. and M.H. are supported by an intramural research funding of the UMC Mainz. M.H. is supported by the Clinician Scientist Fellowship "TransMed Jumpstart Program: 2019_A72" supported by the Else Kröner Fresenius Foundation.

Conflict of interest H.S., M.H., U.N., M.S., S.P., J.H., C.L., and S.G. declare that they have no conflicts of interest that might be relevant to the contents of this manuscript.

Ethics approval Not applicable.

Consent to participate Not applicable.

Consent for publication Not applicable.

Availability of data and material Not applicable.

Code availability Not applicable.

Author contributions Writing and editing by HS, MH, UN, MS, SP, $\mathrm{JH}, \mathrm{CL}$, and SG; figures designed by $\mathrm{MH}$ and $\mathrm{HS}$; supervision by SG and CL. All authors have read and agreed to the version of the manuscript.

Open Access This article is licensed under a Creative Commons Attribution-NonCommercial 4.0 International License, which permits any non-commercial use, sharing, adaptation, distribution and reproduction in any medium or format, as long as you give appropriate credit to the original author(s) and the source, provide a link to the Creative Commons licence, and indicate if changes were made. The images or other third party material in this article are included in the article's Creative Commons licence, unless indicated otherwise in a credit line to the material. If material is not included in the article's Creative Commons licence and your intended use is not permitted by statutory regulation or exceeds the permitted use, you will need to obtain permission directly from the copyright holder. To view a copy of this licence, visit http://creativecommons.org/licenses/by-nc/4.0/.

\section{References}

1. Siegel RL, Miller KD, Jemal A. Cancer statistics, 2019. CA Cancer J Clin. 2019;69(1):7-34.

2. Poklepovic AS, Luke JJ. Considering adjuvant therapy for stage II melanoma. Cancer. 2020;126(6):1166-74.

3. Gershenwald JE, Scolyer RA, Hess KR, Sondak VK, Long GV, Ross MI, et al. Melanoma staging: evidence-based changes in the American Joint Committee on Cancer eighth cancer staging manual. CA Cancer J Clin. 2017;67(6):472-92.

4. Amin MB, Greene FL, Edge SB, Compton CC, Gershenwald JE, Brookland RK, et al. The Eighth edition AJCC Cancer Staging Manual: continuing to build a bridge from a population-based to a more "personalized" approach to cancer staging. CA Cancer J Clin. 2017;67(2):93-9.

5. Karakousis CP, Balch CM, Urist MM, Ross MM, Smith TJ, Bartolucci AA. Local recurrence in malignant melanoma: long-term results of the multiinstitutional randomized surgical trial. Ann Surg Oncol. 1996;3(5):446-52.

6. Faries MB, Thompson JF, Cochran AJ, Andtbacka RH, Mozzillo N, Zager JS, et al. Completion dissection or observation for sentinel-node metastasis in melanoma. N Engl J Med. 2017;376(23):2211-22.

7. Henderson MA, Burmeister BH, Ainslie J, Fisher R, Di Iulio J, Smithers BM, et al. Adjuvant lymph-node field radiotherapy versus observation only in patients with melanoma at high risk of further lymph-node field relapse after lymphadenectomy (ANZMTG 01.02/TROG 02.01): 6-year follow-up of a phase 3, randomised controlled trial. Lancet Oncol. 2015;16(9):1049-60.

8. Burmeister BH, Henderson MA, Ainslie J, Fisher R, Di Iulio J, Smithers BM, et al. Adjuvant radiotherapy versus observation alone for patients at risk of lymph-node field relapse after therapeutic lymphadenectomy for melanoma: a randomised trial. Lancet Oncol. 2012;13(6):589-97.

9. Strojan P. Role of radiotherapy in melanoma management. Radiol Oncol. 2010;44(1):1-12.

10. Rossi CR, Mozzillo N, Maurichi A, Pasquali S, Quaglino P, Borgognoni $\mathrm{L}$, et al. The number of excised lymph nodes is associated with survival of melanoma patients with lymph node metastasis. Ann Oncol. 2014;25(1):240-6.

11. Joo JH, Kim YS, Nam JH. Prognostic significance of lymph node ratio in node-positive cervical cancer patients. Medicine. 2018;97(30):11711.

12. Sandro P, Andrea M, Nicola M, Simone M, Giuseppe M, Lorenzo B, et al. Lymph-node ratio in patients with cutaneous melanoma: a multi-institution prognostic study. Ann Surg Oncol. 2015;22(7):2127-34.

13. Ascierto PA, Borgognoni L, Botti G, Guida M, Marchetti P, Mocellin S, et al. New paradigm for stage III melanoma: from surgery to adjuvant treatment. J Transl Med. 2019;17(1):266.

14. Testori AAE, Chiellino S, van Akkooi ACJ. Adjuvant therapy for nelanoma: past, current, and future developments. Cancers. 2020;12(7):1994.

15. Eggermont AMM, Dummer R. The 2017 complete overhaul of adjuvant therapies for high-risk melanoma and its consequences for staging and management of melanoma patients. Eur J Cancer. 2017;86:101-5.

16. Dickson PV, Gershenwald JE. Staging and prognosis of cutaneous melanoma. Surg Oncol Clin N Am. 2011;20(1):1-17. 
17. Yushak M, Mehnert J, Luke J, Poklepovic A. Approaches to high-risk resected stage II and III melanoma. Am Soc Clin Oncol Educ Book. 2019;39:e207-11.

18. Agarwala SS, Neuberg D, Park Y, Kirkwood JM. Mature results of a phase III randomized trial of bacillus CalmetteGuerin (BCG) versus observation and BCG plus dacarbazine versus BCG in the adjuvant therapy of American Joint Committee on Cancer Stage I-III melanoma (E1673): a trial of the Eastern Oncology Group. Cancer. 2004;100(8):1692-8.

19. Kim KB, Legha SS, Gonzalez R, Anderson CM, Johnson $\mathrm{MM}$, Liu $\mathrm{P}$, et al. A randomized phase III trial of biochemotherapy versus interferon-alpha-2b for adjuvant therapy in patients at high risk for melanoma recurrence. Melanoma Res. 2009;19(1):42-9.

20. Flood BA, Higgs EF, Li S, Luke JJ, Gajewski TF. STING pathway agonism as a cancer therapeutic. Immunol Rev. 2019;290(1):24-38.

21. Schaupp L, Muth S, Rogell L, Kofoed-Branzk M, Melchior F, Lienenklaus S, et al. Microbiota-induced type I interferons instruct a poised basal state of dendritic cells. Cell. 2020;181(5):1080-9619.

22. Raig ET, Jones NB, Varker KA, Benniger K, Go MR, Biber $\mathrm{JL}$, et al. VEGF secretion is inhibited by interferon-alpha in several melanoma cell lines. J Interferon Cytokine Res. 2008;28(9):553-61.

23. Zhou F. Molecular mechanisms of IFN-gamma to up-regulate MHC class I antigen processing and presentation. Int Rev Immunol. 2009;28(3-4):239-60.

24. Eggermont AMM, Suciu S, Santinami M, Testori A, Kruit WHJ, Marsden J, et al. Adjuvant therapy with pegylated interferon alfa$2 \mathrm{~b}$ versus observation alone in resected stage III melanoma: final results of EORTC 18991, a randomised phase III trial. Lancet. 2008;372(9633):117-26.

25. Daud A, Soon C, Dummer R, Eggermont AM, Hwu WJ, Grob JJ, et al. Management of pegylated interferon alpha toxicity in adjuvant therapy of melanoma. Expert Opin Biol Ther. 2012;12(8):1087-99.

26. Eggermont AMM, Suciu S, Rutkowski P, Kruit WH, Punt CJ, Dummer R, et al. Long term follow up of the EORTC 18952 trial of adjuvant therapy in resected stage IIB-III cutaneous melanoma patients comparing intermediate doses of interferonalpha-2b (IFN) with observation: ulceration of primary is key determinant for IFN-sensitivity. Eur J Cancer. 2016;55:111-21.

27. Eggermont AMM, Suciu S, Testori A, Santinami M, Kruit WHJ, Marsden J, et al. Long-term results of the randomized phase III trial EORTC 18991 of adjuvant therapy with pegylated interferon Alfa- $2 \mathrm{~b}$ versus observation in resected stage III melanoma. J Clin Oncol. 2012;30(31):3810-8.

28. Long GV, Stroyakovskiy D, Gogas H, Levchenko E, de Braud F, Larkin J, et al. Combined BRAF and MEK inhibition versus BRAF inhibition alone in melanoma. $\mathrm{N}$ Engl $\mathrm{J}$ Med. 2014;371(20):1877-88.

29. Schachter J, Ribas A, Long GV, Arance A, Grob JJ, Mortier L, et al. Pembrolizumab versus ipilimumab for advanced melanoma: final overall survival results of a multicentre, randomised, open-label phase 3 study (KEYNOTE-006). Lancet. 2017;390(10105):1853-62.

30. Zhang Y, Zheng J. Functions of immune checkpoint molecules beyond immune evasion. Adv Exp Med Biol. 2020;1248:201-26.

31. Dyck L, Mills KHG. Immune checkpoints and their inhibition in cancer and infectious diseases. Eur J Immunol. 2017;47(5):765-79.

32. Pardoll DM. The blockade of immune checkpoints in cancer immunotherapy. Nat Rev Cancer. 2012;12(4):252-64.
33. Ai M, Curran MA. Immune checkpoint combinations from mouse to man. Cancer Immunol Immunother. 2015;64(7):885-92.

34. Topalian SL, Drake CG, Pardoll DM. Immune checkpoint blockade: a common denominator approach to cancer therapy. Cancer Cell. 2015;27(4):450-61.

35. Chen DS, Mellman I. Oncology meets immunology: the cancerimmunity cycle. Immunity. 2013;39(1):1-10.

36. Seidel JA, Otsuka A, Kabashima K. Anti-PD-1 and anti-CTLA-4 therapies in cancer: mechanisms of action, efficacy, and limitations. Front Oncol. 2018;8:86.

37. Ostrov DA, Shi W, Schwartz JC, Almo SC, Nathenson SG. Structure of murine CTLA-4 and its role in modulating T cell responsiveness. Science. 2000;290(5492):816-9.

38. Brunet JF, Denizot F, Luciani MF, Roux-Dosseto M, Suzan M, Mattei MG, et al. A new member of the immunoglobulin superfamily: CTLA-4. Nature. 1987;328(6127):267-70.

39. Walunas TL, Bluestone JA. CTLA-4 regulates tolerance induction and $\mathrm{T}$ cell differentiation in vivo. J Immunol. 1998;160(8):3855-60.

40. Khattri R, Auger JA, Griffin MD, Sharpe AH, Bluestone JA. Lymphoproliferative disorder in CTLA-4 knockout mice is characterized by CD28-regulated activation of Th2 responses. J Immunol. 1999;162(10):5784-91.

41. Tivol EA, Borriello F, Schweitzer AN, Lynch WP, Bluestone JA, Sharpe AH. Loss of CTLA-4 leads to massive lymphoproliferation and fatal multiorgan tissue destruction, revealing a critical negative regulatory role of CTLA-4. Immunity. 1995;3(5):541-7.

42. Christodoulou MI, Zaravinos A. New clinical approaches and emerging evidence on immune-checkpoint inhibitors as anticancer therapeutics: CTLA-4 and PD-1 pathways and beyond. Crit Rev Immunol. 2019;39(5):379-408.

43. Leach DR, Krummel MF, Allison JP. Enhancement of antitumor immunity by CTLA-4 blockade. Science. 1996;271(5256):1734-6.

44. Qin S, Xu L, Yi M, Yu S, Wu K, Luo S. Novel immune checkpoint targets: moving beyond PD-1 and CTLA-4. Mol Cancer. 2019;18(1):155.

45. Hodi FS, O'Day SJ, McDermott DF, Weber RW, Sosman JA, Haanen JB, et al. Improved survival with ipilimumab in patients with metastatic melanoma. N Engl J Med. 2010;363(8):711-23.

46. Eggermont AM, Chiarion-Sileni V, Grob JJ, Dummer R, Wolchok JD, Schmidt H, et al. Adjuvant ipilimumab versus placebo after complete resection of high-risk stage III melanoma (EORTC 18071): a randomised, double-blind, phase 3 trial. Lancet Oncol. 2015;16(5):522-30.

47. Tarhini AA, Lee SJ, Hodi FS, Rao UNM, Cohen GI, Hamid $\mathrm{O}$, et al. Phase III study of adjuvant ipilimumab (3 or $10 \mathrm{mg}$ / $\mathrm{kg}$ ) versus high-dose interferon alfa- $2 \mathrm{~b}$ for resected high-risk melanoma: North American Intergroup E1609. J Clin Oncol. 2020;38(6):567-75.

48. Weber J, Mandala M, Del Vecchio M, Gogas HJ, Arance $\mathrm{AM}$, Cowey $\mathrm{CL}$, et al. Adjuvant nivolumab versus ipilimumab in resected stage III or IV melanoma. N Engl J Med. 2017;377(19):1824-35.

49. Khunger A, Buchwald ZS, Lowe M, Khan MK, Delman KA, Tarhini AA. Neoadjuvant therapy of locally/regionally advanced melanoma. Ther Adv Med Oncol. 2019;11:1758835919866959.

50. Hao C, Tian J, Liu H, Li F, Niu H, Zhu B. Efficacy and safety of anti-PD-1 and anti-PD-1 combined with anti-CTLA-4 immunotherapy to advanced melanoma: a systematic review and meta-analysis of randomized controlled trials. Medicine. 2017;96(26):7325.

51. Carter L, Fouser LA, Jussif J, Fitz L, Deng B, Wood CR, et al. PD-1:PD-L inhibitory pathway affects both CD4(+) and CD8(+) T cells and is overcome by IL-2. Eur J Immunol. 2002;32(3):634-43. 
52. Freeman GJ, Long AJ, Iwai Y, Bourque K, Chernova T, Nishimura H, et al. Engagement of the PD-1 immunoinhibitory receptor by a novel B7 family member leads to negative regulation of lymphocyte activation. J Exp Med. 2000;192(7):1027-34.

53. LaFleur MW, Muroyama Y, Drake CG, Sharpe AH. Inhibitors of the PD-1 pathway in tumor therapy. J Immunol. 2018;200(2):375-83.

54. Francisco LM, Sage PT, Sharpe AH. The PD-1 pathway in tolerance and autoimmunity. Immunol Rev. 2010;236:219-42.

55. Iwai Y, Ishida M, Tanaka Y, Okazaki T, Honjo T, Minato N. Involvement of PD-L1 on tumor cells in the escape from host immune system and tumor immunotherapy by PD-L1 blockade. Proc Natl Acad Sci USA. 2002;99(19):12293-7.

56. Hino R, Kabashima K, Kato Y, Yagi H, Nakamura M, Honjo $\mathrm{T}$, et al. Tumor cell expression of programmed cell death-1 ligand 1 is a prognostic factor for malignant melanoma. Cancer. 2010;116(7):1757-66.

57. Hamanishi J, Mandai M, Iwasaki M, Okazaki T, Tanaka Y, Yamaguchi K, et al. Programmed cell death 1 ligand 1 and tumorinfiltrating CD8+ T lymphocytes are prognostic factors of human ovarian cancer. Proc Natl Acad Sci USA. 2007;104(9):3360-5.

58. Liang SC, Latchman YE, Buhlmann JE, Tomczak MF, Horwitz BH, Freeman GJ, et al. Regulation of PD-1, PD-L1, and PD-L2 expression during normal and autoimmune responses. Eur $\mathbf{J}$ Immunol. 2003;33(10):2706-16.

59. Boussiotis VA, Chatterjee P, Li L. Biochemical signaling of PD-1 on T cells and its functional implications. Cancer J. 2014;20(4):265-71.

60. Hirsch I, Janovec V, Stranska R, Bendriss-Vermare N. Cross talk between inhibitory immunoreceptor tyrosine-based activation motif-signaling and Toll-like receptor pathways in macrophages and dendritic cells. Front Immunol. 2017;8(394):394.

61. Campbell KS, Dessing M, Lopez-Botet M, Cella M, Colonna M. Tyrosine phosphorylation of a human killer inhibitory receptor recruits protein tyrosine phosphatase 1C. J Exp Med. 1996;184(1):93-100.

62. Boonen GJ, van Dijk AM, Verdonck LF, van Lier RA, Rijksen G, Medema RH. CD28 induces cell cycle progression by IL2-independent down-regulation of p27kip1 expression in human peripheral T lymphocytes. Eur J Immunol. 1999;29(3):789-98.

63. Sherr CJ, Roberts JM. Living with or without cyclins and cyclindependent kinases. Genes Dev. 2004;18(22):2699-711.

64. Unkeless JC, Jin J. Inhibitory receptors, ITIM sequences and phosphatases. Curr Opin Immunol. 1997;9(3):338-43.

65. Shi Y. Regulatory mechanisms of PD-L1 expression in cancer cells. Cancer Immunol Immunother. 2018;67(10):1481-9.

66. Trautmann L, Janbazian L, Chomont N, Said EA, Gimmig S, Bessette B, et al. Upregulation of PD-1 expression on HIV-specific CD8+ T cells leads to reversible immune dysfunction. Nat Med. 2006;12(10):1198-202.

67. Weber JS, Del Vecchio M, Mandala M, Gogas H, Arance AM, Dalle S, et al. Adjuvant nivolumab (NIVO) versus ipilimumab (IPI) in resected stage III/IV melanoma: 3-year efficacy and biomarker results from the phase III CheckMate 238 trial. Ann Oncol. 2019;30(Suppl_5):533.

68. Urbani S, Amadei B, Tola D, Massari M, Schivazappa S, Missale $\mathrm{G}$, et al. PD-1 expression in acute hepatitis $\mathrm{C}$ virus (HCV) infection is associated with HCV-specific CD8 exhaustion. J Virol. 2006;80(22): 11398-403.

69. Ascierto PA, Del Vecchio M, Mandala M, Gogas H, Arance $\mathrm{AM}$, Dalle S, et al. Adjuvant nivolumab versus ipilimumab in resected stage IIIB-C and stage IV melanoma (CheckMate 238): 4-year results from a multicentre, doubleblind, randomised, controlled, phase 3 trial. Lancet Oncol. 2020;21(11):1465-77.
70. Cohen JV, Buchbinder EI. The evolution of adjuvant therapy for melanoma. Curr Oncol Rep. 2019;21(12):106.

71. Eggermont AMM, Blank CU, Mandalà M, Long GV, Atkinson VG, Dalle S, et al. Adjuvant pembrolizumab versus placebo in resected stage III melanoma (EORTC 1325-MG/KEYNOTE-054): distant metastasis-free survival results from a double-blind, randomised, controlled, phase 3 trial. Lancet Oncol. 2021;22(5):643-54.

72. Eggermont AMM, Blank CU, Mandala M, Long GV, Atkinson VG, Dalle S, et al. Longer follow-up confirms recurrence-free survival benefit of adjuvant pembrolizumab in high-risk stage III melanoma: updated results from the EORTC 1325-MG/KEYNOTE-054 Trial. J Clin Oncol. 2020;38(33):3925-36.

73. Eggermont AMM, Blank CU, Mandala M, Long GV, Atkinson V, Dalle S, et al. Adjuvant pembrolizumab versus placebo in resected stage III melanoma. N Engl J Med. 2018;378(19):1789-801.

74. Tarhini AA. The current state of adjuvant therapy of melanoma. Lancet Oncol. 2020;21(11):1394-5.

75. Long GV, Tykodi SS, Schneider JG, Garbe C, Gravis G, Rashford $\mathrm{M}$, et al. Assessment of nivolumab exposure and clinical safety of $480 \mathrm{mg}$ every 4 weeks flat-dosing schedule in patients with cancer. Ann Oncol. 2018;29(11):2208-13.

76. Long GV, Hauschild A, Santinami M, Atkinson V, Mandala M, Chiarion-Sileni V, et al. Adjuvant dabrafenib plus trametinib in stage III BRAF-mutated melanoma. N Engl J Med. 2017;377(19):1813-23

77. Maio M, Lewis K, Demidov L, Mandala M, Bondarenko I, Ascierto PA, et al. Adjuvant vemurafenib in resected, BRAF(V600) mutation-positive melanoma (BRIM8): a randomised, double-blind, placebo-controlled, multicentre, phase 3 trial. Lancet Oncol. 2018;19(4):510-20.

78. Huang AC, Orlowski RJ, Xu X, Mick R, George SM, Yan $\mathrm{PK}$, et al. A single dose of neoadjuvant PD-1 blockade predicts clinical outcomes in resectable melanoma. Nat Med. 2019;25(3):454-61.

79. Amaria RN, Reddy SM, Tawbi HA, Davies MA, Ross MI, Glitza IC, et al. Neoadjuvant immune checkpoint blockade in high-risk resectable melanoma. Nat Med. 2018;24(11):1649-54.

80. Blank CU, Rozeman EA, Fanchi LF, Sikorska K, van de Wiel B, Kvistborg P, et al. Neoadjuvant versus adjuvant ipilimumab plus nivolumab in macroscopic stage III melanoma. Nat Med. 2018;24(11):1655-61.

81. Rozeman EA, Menzies AM, van Akkooi ACJ, Adhikari C, Bierman C, van de Wiel BA, et al. Identification of the optimal combination dosing schedule of neoadjuvant ipilimumab plus nivolumab in macroscopic stage III melanoma (OpACIN-neo): a multicentre, phase 2, randomised, controlled trial. Lancet Oncol. 2019;20(7):948-60.

82. Long GV, Saw RPM, Lo S, Nieweg OE, Shannon KF, Gonzalez $\mathrm{M}$, et al. Neoadjuvant dabrafenib combined with trametinib for resectable, stage IIIB-C, BRAF(V600) mutation-positive melanoma (NeoCombi): a single-arm, open-label, single-centre, phase 2 trial. Lancet Oncol. 2019;20(7):961-71.

83. Zimmer L, Livingstone E, Hassel JC, Fluck M, Eigentler $\mathrm{T}$, Loquai $\mathrm{C}$, et al. Adjuvant nivolumab plus ipilimumab or nivolumab monotherapy versus placebo in patients with resected stage IV melanoma with no evidence of disease (IMMUNED): a randomised, double-blind, placebo-controlled, phase 2 trial. Lancet. 2020;395(10236):1558-68.

84. Davies H, Bignell GR, Cox C, Stephens P, Edkins S, Clegg S, et al. Mutations of the BRAF gene in human cancer. Nature. 2002;417(6892):949-54.

85. Schadendorf D, Fisher DE, Garbe C, Gershenwald JE, Grob JJ, Halpern A, et al. Melanoma. Nat Rev Dis Primers. 2015;1:15003. 
86. Dummer R, Hauschild A, Santinami M, Atkinson V, Mandalà M, Kirkwood JM, et al. Five-year analysis of adjuvant dabrafenib plus trametinib in stage III melanoma. N Engl J Med. 2020;383(12):1139-48.

87. Manola J, Atkins M, Ibrahim J, Kirkwood J. Prognostic factors in metastatic melanoma: a pooled analysis of Eastern Cooperative Oncology Group trials. J Clin Oncol. 2000;18(22):3782-93.

88. Romano E, Scordo M, Dusza SW, Coit DG, Chapman PB. Site and timing of first relapse in stage III melanoma patients: implications for follow-up guidelines. J Clin Oncol. 2010;28(18):3042-7.

89. Madu MF, Franke V, Van de Wiel BA, Klop WMC, Jozwiak K, van Houdt WJ, et al. External validation of the American Joint Committee on Cancer 8th edition melanoma staging system: who needs adjuvant treatment? Melanoma Res. 2020;30(2):185-92.

90. Kanaki T, Stang A, Gutzmer R, Zimmer L, Chorti E, Sucker A, et al. Impact of American Joint Committee on Cancer 8th edition classification on staging and survival of patients with melanoma. Eur J Cancer. 2019;119:18-29.

91. Kwak M, Farrow NE, Salama AKS, Mosca PJ, Hanks BA, Slingluff CL, et al. Updates in adjuvant systemic therapy for melanoma. J Surg Oncol. 2019;119(2):222-31.

92. Estevez LG, Gradishar WJ. Evidence-based use of neoadjuvant taxane in operable and inoperable breast cancer. Clin Cancer Res. 2004;10(10):3249-61.

93. Wang M, Hou L, Chen M, Zhou Y, Liang Y, Wang S, et al. Neoadjuvant chemotherapy creates surgery opportunities for inoperable locally advanced breast cancer. Sci Rep. 2017;7:44673.

94. Huber K. Cancer of the esophagus and gastroesophageal junction: improved survival with neoadjuvant radiochemotherapy. Strahlenther Onkol. 2013;189(2):161-2.

95. Al-Batran SE, Hofheinz RD, Pauligk C, Kopp HG, Haag GM, Luley $\mathrm{KB}$, et al. Histopathological regression after neoadjuvant docetaxel, oxaliplatin, fluorouracil, and leucovorin versus epirubicin, cisplatin, and fluorouracil or capecitabine in patients with resectable gastric or gastro-oesophageal junction adenocarcinoma (FLOT4-AIO): results from the phase 2 part of a multicentre, open-label, randomised phase 2/3 trial. Lancet Oncol. 2016;17(12):1697-708.

96. Dede K, Lang I, Porneczi B, Mester G, Fekete A, Koszegi G, et al. Preoperative chemotherapy in the surgical treatment of colorectal liver metastases. Magy Seb. 2013;66(6):325-30.

97. Amaria RN, Menzies AM, Burton EM, Scolyer RA, Tetzlaff MT, Antdbacka R, et al. Neoadjuvant systemic therapy in melanoma: recommendations of the International Neoadjuvant Melanoma Consortium. Lancet Oncol. 2019;20(7):e378-89.

98. Carlino MS, Long GV, Schadendorf D, Robert C, Ribas A, Richtig E, et al. Outcomes by line of therapy and programmed death ligand 1 expression in patients with advanced melanoma treated with pembrolizumab or ipilimumab in KEYNOTE-006: a randomised clinical trial. Eur J Cancer. 2018;101:236-43.

99. Blank CU, Versluis JM, Rozeman EA, Menzies AM, Reijers IL, Krijgsman O, et al. Abstract 3412: 36-months and 18-months relapse-free survival after (neo)adjuvant ipilimumab plus nivolumab in macroscopic stage III melanoma patients: update of the OpACIN and OpACIN-neo trials. Cancer Res. 2020;80(Suppl_16):3412.

100. Tetzlaff MT, Messina JL, Stein JE, Xu X, Amaria RN, Blank $\mathrm{CU}$, et al. Pathological assessment of resection specimens after neoadjuvant therapy for metastatic melanoma. Ann Oncol. 2018;29(8):1861-8.

101. Blank CU, Reijers ILM, Pennington T, Versluis JM, Saw RPM, Rozeman EA, et al. First safety and efficacy results of PRADO: a phase II study of personalized response-driven surgery and adjuvant therapy after neoadjuvant ipilimumab (IPI) and nivolumab (NIVO) in resectable stage III melanoma. J Clin Oncol. 2020;38(15):10002.

102. Amaria RN, Prieto PA, Tetzlaff MT, Reuben A, Andrews MC, Ross MI, et al. Neoadjuvant plus adjuvant dabrafenib and trametinib versus standard of care in patients with high-risk, surgically resectable melanoma: a single-centre, open-label, randomised, phase 2 trial. Lancet Oncol. 2018;19(2):181-93.

103. Long GV, Eroglu Z, Infante J, Patel S, Daud A, Johnson DB, et al. Long-term outcomes in patients with BRAF V600-mutant metastatic melanoma who received dabrafenib combined with trametinib. J Clin Oncol. 2018;36(7):667-73.

104. Meirson T, Asher N, Bomze D, Markel G. Safety of BRAF+MEK inhibitor combinations: severe adverse event evaluation. Cancers (Basel). 2020;12(6):1650.

105. Bronte E, Bronte G, Novo G, Rinaldi G, Bronte F, Passiglia F, et al. Cardiotoxicity mechanisms of the combination of BRAF-inhibitors and MEK-inhibitors. Pharmacol Ther. 2018;192:65-73.

106. Johnson DB, Sullivan RJ, Menzies AM. Immune checkpoint inhibitors in challenging populations. Cancer. 2017;123(11):1904-11.

107. Granier C, Karaki S, Roussel H, Badoual C, Tran T, Anson $\mathrm{M}$, et al. Cancer immunotherapy: rational and recent breakthroughs. Rev Med Interne. 2016;37(10):694-700.

108. Testori AAE, Chiellino S, van Akkooi ACJ. Adjuvant therapy for melanoma: past, current, and future developments. Cancers (Basel). 2020;12(7):1994.

109. Ho PC, Meeth KM, Tsui YC, Srivastava B, Bosenberg MW, Kaech SM. Immune-based antitumor effects of BRAF inhibitors rely on signaling by CD40L and IFNgamma. Cancer Res. 2014;74(12):3205-17.

110. Sumimoto H, Imabayashi F, Iwata $T$, Kawakami Y. The BRAF-MAPK signaling pathway is essential for cancerimmune evasion in human melanoma cells. J Exp Med. 2006;203(7):1651-6.

111. Ott PA, Henry T, Baranda SJ, Frleta D, Manches O, Bogunovic $\mathrm{D}$, et al. Inhibition of both BRAF and MEK in BRAF(V600E) mutant melanoma restores compromised dendritic cell (DC) function while having differential direct effects on DC properties. Cancer Immunol Immunother. 2013;62(4):811-22.

112. Frederick DT, Piris A, Cogdill AP, Cooper ZA, Lezcano C, Ferrone $\mathrm{CR}$, et al. BRAF inhibition is associated with enhanced melanoma antigen expression and a more favorable tumor microenvironment in patients with metastatic melanoma. Clin Cancer Res. 2013;19(5):1225-31.

113. Hu-Lieskovan S, Mok S, Homet Moreno B, Tsoi J, Robert L, Goedert L, et al. Improved antitumor activity of immunotherapy with BRAF and MEK inhibitors in BRAF(V600E) melanoma. Sci Transl Med. 2015;7(279):279ra41.

114. Johnson DB, Pectasides E, Feld E, Ye F, Zhao S, Johnpulle R, et al. Sequencing treatment in BRAFV600 mutant melanoma: anti-PD- 1 before and after BRAF inhibition. J Immunother. 2017;40(1):31-5.

115. Pavlick AC, Fecher L, Ascierto PA, Sullivan RJ. Frontline therapy for BRAF-mutated metastatic melanoma: how do you choose, and is there one correct answer? Am Soc Clin Oncol Educ Book. 2019;39:564-71.

116. Menzies AM, Rozeman EA, Amaria RN, Huang ACC, Scolyer RA, Tetzlaff MT, et al. Pathological response and survival with neoadjuvant therapy in melanoma: a pooled analysis from the International Neoadjuvant Melanoma Consortium (INMC). J Clin Oncol. 2019;37(Suppl_15):9503.

117. Garutti M, Buriolla S, Bertoli E, Vitale MG, Rossi E, Schinzari G, et al. "To anticipate": neoadjuvant therapy in melanoma with a focus on predictive biomarkers. Cancers (Basel). 2020;12(7):1941. 
118. Keung EZ, Amaria RN, Sondak VK, Ross MI, Kirkwood JM, Wargo JA, et al. Neoadjuvant systemic therapy for highrisk melanoma patients. In: Balch CM, Atkins MB, Garbe C,
Gershenwald JE, Halpern AC, Kirkwood JM, et al., editors. Cutaneous melanoma. Cham: Springer International Publishing; 2020. p. 767-93. 